\title{
A rock-magnetic and paleointensity study of some Mexican volcanic lava flows during the Latest Pleistocene to the Holocene
}

\author{
Juan Morales, Avto Goguitchaichvili, and Jaime Urrutia-Fucugauchi \\ Laboratorio de Paleomagnetismo y Geofisica Nuclear, Instituto de Geofisica, UNAM, Ciudad Universitaria, 04510 México DF, Mexico
}

(Received September 26, 2000; Revised May 28, 2001; Accepted May 31, 2001)

\begin{abstract}
Eleven Late Quaternary lava flows were sampled in the Chichinautzin volcanic field of central Mexico to determine their magnetic characteristics and absolute paleointensity. The samples studied cover a geological time interval of approximately 0.39 My to 2000 years. Several rock-magnetic experiments were carried out in order to identify the magnetic carriers and to obtain information about their paleomagnetic stability. Continuous susceptibility measurements with temperature in most cases yield reasonably reversible curves with Curie points close to that of almost pure magnetite, which is compatible with low-Ti titanomagnetite resulting from oxi-exsolution. Judging from the ratios of hysteresis parameters, it seems that all samples fall within the pseudo-single domain grain size region, probably indicating a mixture of multidomain and a significant amount of single domain grains. Forty-two samples belonging to six independent cooling units yielded acceptable absolute paleointensity estimates. The NRM fractions used for paleointensity determination range from 0.34 to 0.97 and the quality factors varies between 4.5 and 97.8 , being normally greater than 5 . The obtained virtual dipole moment values are higher than those recently reported for the past $5 \mathrm{My}$ and to the present day geomagnetic field strength. Individual paleointensity of around $2000 \mathrm{BP}$ is substantially higher than the present day intensity, which is in broad agreement with worldwide archeomagnetic results.
\end{abstract}

\section{Introduction}

The study of absolute paleointensity variation can provide powerful constraints of the physics of the Earth's deep interior and the functioning of the geodynamo. Glatzmaier et al. (1999) and Coe et al. (2000) recently suggested that absolute intensity should be a fundamental constraint in the recent numerical models that promise to provide unprecedented insight into the operation of the geodynamo. Despite about 40 years of research, paleointensity data are scarce (Perrin and Shcherbakov, 1997) and cannot be yet used to document a long-term variation in the intensity of the Earth's magnetic field through geological time. The major reason for the small number of determinations is that paleointensity is the most difficult component of the magnetic field to determine and the failure rate is often large, generally in the order of $80 \%$ (Kosterov and Prévot, 1998).

Prévot et al. (1990) first underlined the existence of a relatively low field during the Mesozoic time. However, little is known about the transition mode between the Mesozoic low and present-day 'high' field, largely because of the limited amount of reliable data available. Based on a paleointensity study of submarine basaltic glass, Juàrez and Tauxe (2000) argued that the geomagnetic field strength may have been also substantially low during the Plio-Quaternary time (from 5 to $0.3 \mathrm{My}$ and maybe for the last $160 \mathrm{My}$ ), which is in disagreement with the value of approximately $8.2 \times 10^{22} \mathrm{Am}^{2}$ often quoted for the last $5 \mathrm{My}$ (see, i.e., Goguitchaichvili et

Copy right (c) The Society of Geomagnetism and Earth, Planetary and Space Sciences (SGEPSS); The Seismological Society of Japan; The Volcanological Society of Japan; The Geodetic Society of Japan; The Japanese Society for Planetary Sciences. $a l ., 1999)$. Although numerous absolute intensity determinations are available for the last $50 \mathrm{ky}$, little is known about the paleostrength of the geomagnetic field during this period, mainly because of unusually high dispersion (Perrin and Shcherbakov, 1997; Perrin et al., 1998). This high dispersion of paleointensity results may be due to from some experimental artifacts and not from the geomagnetic field. In this paper, we report a detailed rock-magnetic and paleointensity study for central Mexican Latest Pleistocene to Holocene volcanic lava flows. The principal objective of this study was to obtain a reliable absolute intensity for the last $50 \mathrm{ky}$ and also to contribute to the archeomagnetism of Mesoamerica, since some of the units studied erupted during this historic time.

\section{Sampling Details}

The volcanic lava flows selected for the study are located in the southern part of the Basin of Mexico. All sites belong to the Sierra Chichinautzin group (Fig. 1), which represent the youngest eruptive activity in the Trans Mexican Volcanic Belt. The eruptive phase of this group probably occurred between the Pleistocene and Holocene times (UrrutiaFucugauchi and Martin del Pozzo, 1993). These monogenetic volcanoes which outcrop around Mexico City, seem to originate from the subduction of the Cocos Plate under southern Mexico. Volcanic activity developed during the Brunhes geomagnetic period and is likely younger than $40 \mathrm{Kyr}$ in the northern Chichinautzin Sierra (UrrutiaFucugauchi, 1996; Urrutia-Fucugauchi and Martin del Pozzo, 1993; Gonzalez-Huesca, 1992; Gonzalez-Huesca et 


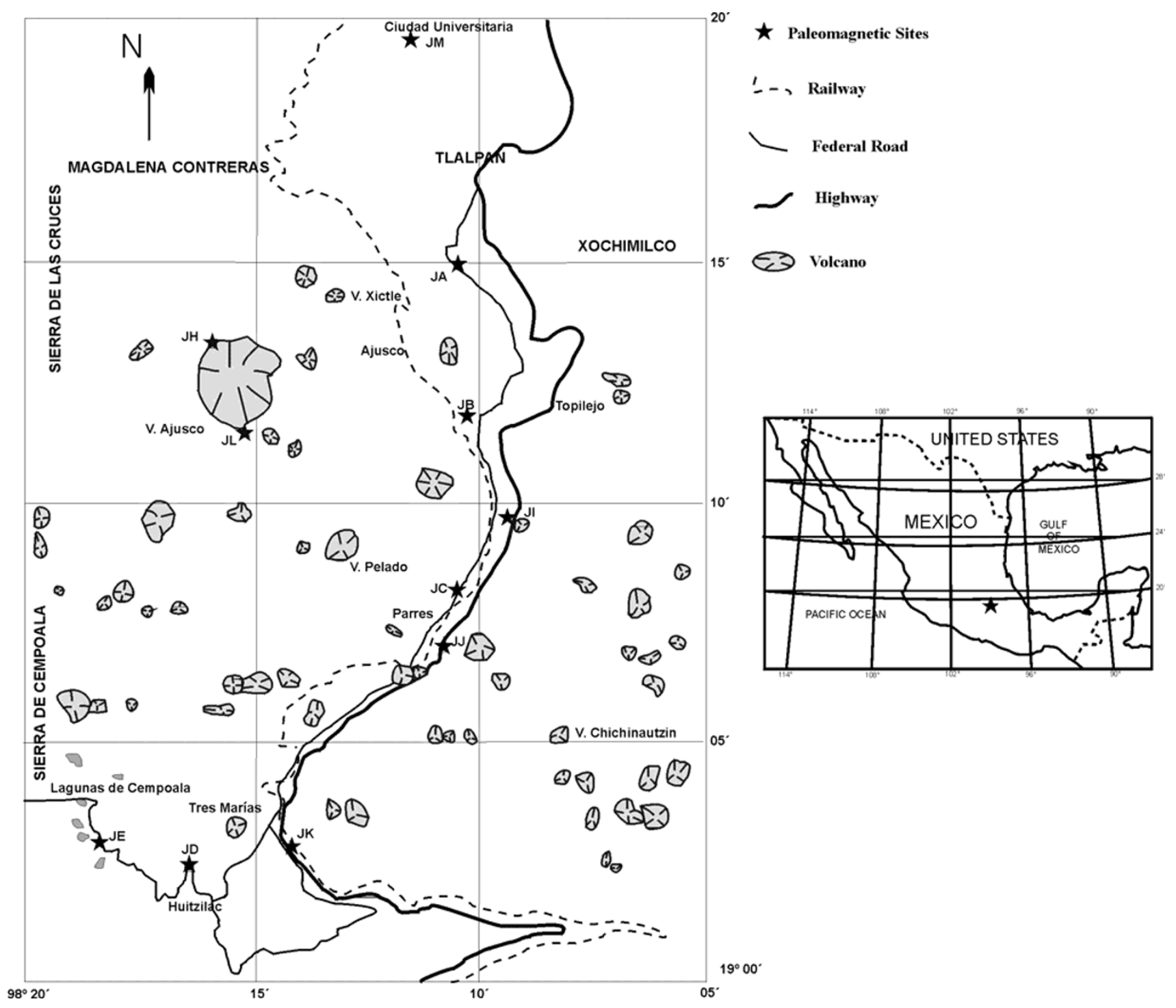

Fig. 1. Schematic map showing the locations of the paleomagnetic sites (stars).

Table 1. Averaged paleodirection of cleaned remanence and corresponding virtual geomagnetic pole (VGP) positions for central Mexican Late Quaternary volcanics. Lat. N and Lon. W are the geographic latitude (north) and longitude (west) of the studied sites. $N$, number of specimens used for calculation; Dec, declination; Inc, inclination. $k$ and $\alpha_{95}$ : precision parameter and radius of $95 \%$ confidence cone of Fisher statistics, Plat/Plong: latitude/longitude of the VGP position, Age: radiometric ages as reported in (1) Gonzalez-Huesca et al. (1997), (2) Urrutia-Fucugauchi and Martin del Pozzo (1993), (3) Mora-Alvarez et al. (1991), (4) Böhnel et al. (1997), and (5) Urrutia-Fucugauchi (1996), Method: radiometric method used for the dating. *In some cases, we demagnetized two samples per core (one by alternating fields and the other one by temperatures) but best quality demagnetization was used for paleomagnetic analyses.

\begin{tabular}{cccccccccccccc}
\hline Site & Volcan & Lat. N & Lon. W & \multicolumn{1}{c}{$N$} & \multicolumn{1}{c}{ Dec } & \multicolumn{1}{c}{ Inc } & $k$ & $\alpha_{95}$ & Plat & Plong & Age (Years BP) & Method & Ref. \\
\hline JB & Pelado & $19^{\circ} .11^{\prime} .14^{\prime \prime}$ & $99^{\circ} .10^{\prime} .15^{\prime \prime}$ & 8 & 10.4 & 17.0 & 198 & 3.9 & 75.6 & 35.2 & $4070 \pm 150$ & ${ }^{14} \mathrm{C}$ & 1 \\
JD & Huilote & $19^{\circ} .02^{\prime} .05^{\prime \prime}$ & $99^{\circ} .16^{\prime} .19^{\prime \prime}$ & 8 & 13.8 & 10.8 & 353 & 3.0 & 70.9 & 34.4 & $<10000$ & 2 \\
JE & Huilote & $19^{\circ} .02^{\prime} .06^{\prime \prime}$ & $99^{\circ} .18^{\prime} .25^{\prime \prime}$ & 8 & 4.0 & 23.1 & 277 & 3.3 & 82.0 & 51.7 & $<10000$ & 2 \\
JH & Ajusco & $19^{\circ} .13^{\prime} .12^{\prime \prime}$ & $99^{\circ} .16^{\prime} .24^{\prime \prime}$ & 8 & 342.7 & 21.5 & 371 & 2.9 & 71.6 & 148.3 & $39000 \pm 160$ & $\mathrm{~K}-\mathrm{Ar}$ & 3 \\
JJ & Acopiaxco & $19^{\circ} .06^{\prime} .60^{\prime \prime}$ & $99^{\circ} .10^{\prime} .54^{\prime \prime}$ & 13 & 352.8 & 33.0 & 498 & 1.9 & 83.1 & 163.7 & $<39000$ & 2 & 3 \\
JL & Ajusco & $19^{\circ} .11^{\prime} .55^{\prime \prime}$ & $99^{\circ} .15^{\prime} .00^{\prime \prime}$ & 10 & 358.8 & 45.0 & 131 & 4.2 & 82.4 & 152.9 & $18680 \pm 120$ & $14 \mathrm{C}$ & 2 \\
JM & Xitle & $19^{\circ} .19^{\prime} .19^{\prime \prime}$ & $99^{\circ} .11^{\prime} .22^{\prime \prime}$ & 13 & 352.0 & 36.0 & 269 & 2.5 & 82.4 & 179.6 & $2030 \pm 60$ & $14 \mathrm{C}$ & 4,5 \\
\hline
\end{tabular}



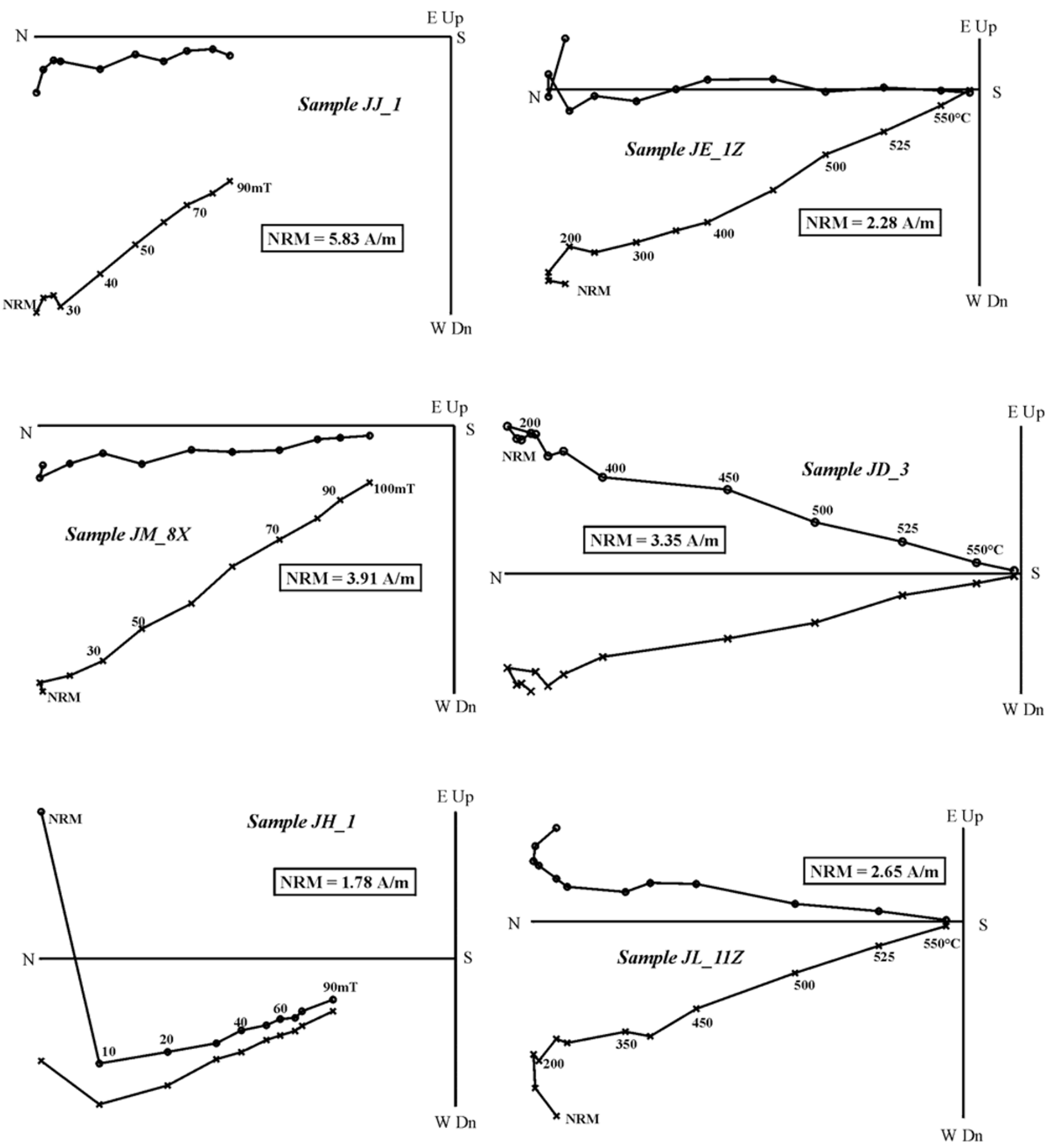

Fig. 2. Orthogonal vector plots of stepwise alternating fields (samples JJ_1, JM_8X and JH_1) and thermal (samples JE_1Z, JD_3, JL_11Z) demagnetization of representative samples (stratigraphic coordinates). The numbers refer to the alternating fields in $\mathrm{mT}$ or to temperatures in ${ }^{\circ} \mathrm{C}$. $\circ$-projections in the horizontal plane, $x$-projections in the vertical plane.

al., 1997; Mora-Alvarez et al., 1991). The radiometric dates (using ${ }^{14} \mathrm{C}$ and $\mathrm{K}-\mathrm{Ar}$ systematics) are available for four out of the seven studied sites (Table 1). Only the relative ages are known for the three remaining volcanic lava flows. The former ages are based on geological observations and previous paleomagnetic studies (Urrutia-Fucugauchi and Martin del Pozzo, 1993). The major-element geochemistry of the lavas was determined by Gonzalez-Huesca (1992) using an atomic absorption spectrometer. When $\mathrm{K} 2 \mathrm{O}$ is plotted against the silica content, all the lavas fall into the Cal- calkaline field with basalts and basalt-andesites.

In total, 120 oriented cores belonging to 11 lava flows were collected. Commonly, the outcrops extend laterally over a few tens of meters. In these cases, we drilled 7-15 standard paleomagnetic cores per volcanic unit. The samples were distributed throughout each flow, both horizontally and vertically in order to minimize the effects of block tilting and lightning. Cores were obtained with a gasolinepowdered portable drill, and then in most cases oriented with both magnetic and Sun compasses. 


\section{Paleodirections}

Remanence measurements were made using a Molspin spinner magnetometer (sensitivity $\sim 10^{-8} \mathrm{Am}^{2}$ ). For one sample per site, stepwise thermal treatment up to $580^{\circ} \mathrm{C}$ was carried out using a Schonstedt furnace with a residual magnetic field of about $15 \mathrm{nT}$. After each heating step, the low field susceptibility was measured at room temperature using a Bartington MS2 susceptibility meter in order to check for possible magnetic changes. For the remaining samples, stepwise alternating field (AF) cleaning was carried out using a laboratory-made AF demagnetizer providing fields of up to $100 \mathrm{mT}$. Heatings were performed in air.

Natural remanent magnetization (NRM) measurements showed that four of the 11 sampled sites, were characterized by unusually high intensity (more than $100 \mathrm{~A} / \mathrm{m}$ ) and very scattered NRM directions. Both factors may point to a strong lightning-produced magnetization overprint. These samples were rejected for further paleomagnetic analyses. The remaining sites yielded reasonably small within-site NRM direction scatter with $\alpha_{95}$ less than $11^{\circ}$. All 65 samples, belonging to these seven volcanic lava flows, were subjected to detailed magnetic cleaning. Almost all of them carry essentially a single component magnetization, observed upon both alternating field and thermal treatments (Fig. 2). A secondary component, probably of viscous origin, is sometime present and easily removed when applying $10 \mathrm{mT}$ (Fig. 2, sample JH_1) or $200^{\circ} \mathrm{C}$ (sample JL_11Z). The median destructive fields (MDF) range mostly between 50 and $70 \mathrm{mT}$, suggesting 'small' pseudo-single domain grains as remanent magnetization carriers (Dunlop and Özdemir, 1997). Some (titano)hematites, together with titanomagnetites, may be present judging from the relatively high coercivity observed. However, we could not detect the presence of (titano)hematites during microscopic observations under reflected light. It is worth noting that the size of the magnetic grains is often too small and the petrologi-

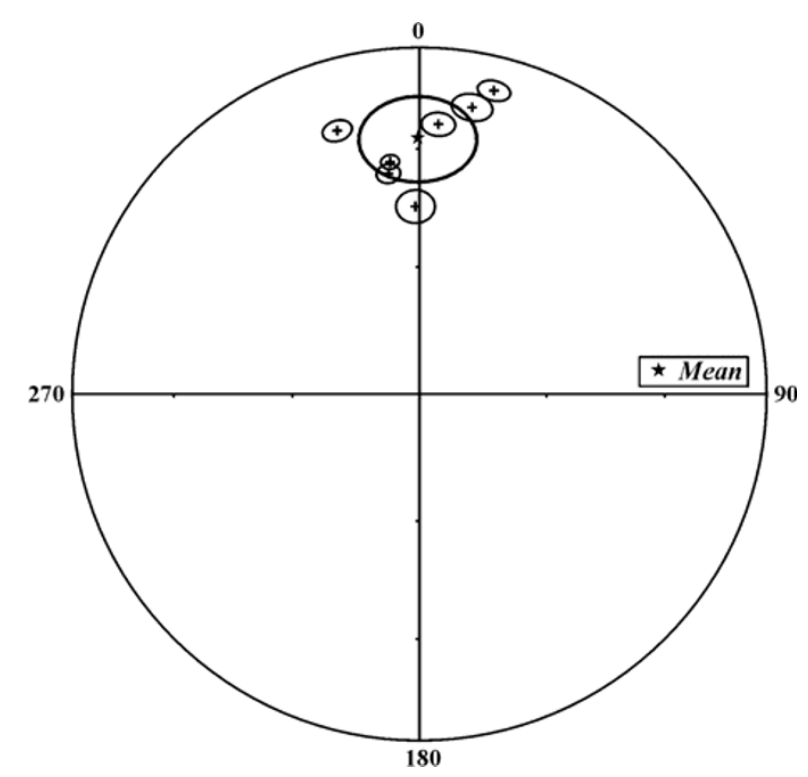

Fig. 3. Equal area projections of the site mean characteristic paleodirections with $\alpha_{95}$ (radius of $95 \%$ confidence cone of Fisher statistics). cal/optical observations of larger ferrimagnetic minerals may not completely correlate with the magnetic behavior of the whole rock. The greater part of the remanence was demagnetized at temperatures of between 500 and $550^{\circ} \mathrm{C}$ (Fig. 2, samples JE_1Z, JD_3 and JL_11Z), which is common for Ti-poor titanomagnetite resulting from oxyexsolution. These observations are compatible with thermomagnetic experiments (see below).

The primary magnetization direction was determined by the least-squares method (Kirschvink, 1980), four to nine points being taken for this determination. In some cases, we demagnetized two samples per core (one by alternating fields and the other by temperatures) but best-quality demagnetization was used for paleomagnetic analyses. The obtained directions were averaged by unit and the statistical parameters calculated assuming a Fisherian distribution. The average flow paleodirections are precisely determined (Table 1 and Fig. 3). $\alpha_{95}$ ranges between $1.9^{\circ}$ and $4.2^{\circ}$, which corresponds to the high quality paleomagnetic data.

\section{Rock-Magnetic Properties}

\subsection{Continuous susceptibility measurements}

Low-field susceptibility measurements ( $k-T$ curves) in the air were carried out to identify the magnetic minerals carrying the remanence and to check their thermal stability. All specimens were heated up to about $600^{\circ} \mathrm{C}$ at a heating rate of $20^{\circ} \mathrm{C} / \mathrm{min}$ and then cooled at the same rate using a Highmoore susceptibility bridge equipped with a furnace in a Mexico City laboratory. The Curie temperature was determined by the method of Prévot et al. (1983). Alternatively, low-temperature (from about $-190^{\circ} \mathrm{C}$ to room temperature) susceptibility was recorded using the same apparatus.

Two different types of behavior were observed during low-T susceptibility experiments (Fig. 4): more than half of the studied samples showed a rather monotonic decrease from about $-185^{\circ} \mathrm{C}$ to room temperature (Site JJ) yielding a very poorly defined inflection point at about $-145^{\circ} \mathrm{C}$. In the other cases, a rather well-defined pick was observed around $-100^{\circ} \mathrm{C}$ (Fig. 4, Site $\mathrm{JH}$ ). In both cases, titaniumpoor titanomagnetite may be responsible for remanent magnetization. As showed by Özdemir et al. (1993), the Verwey transition may be largely suppressed for the titanomagnetites with variable titanium content. Alternatively, similar behavior may also belong to non-stoichiometric (partially oxidized) magnetite. In one case, a quite well defined minimum was detected (site $\mathrm{JH}$ ) at $-60^{\circ} \mathrm{C}$. This temperature is substantially different from the Morin transition observed for pure hematite (around $-15^{\circ}$, after Dunlop and Özdemir, 1997). Only speculatively can we attribute this minimum to the presence of some (titano)hematites. Let us mention that there is a great deficit in rock-magnetic literature about the interpretation of low-temperature continuous susceptibility curves from natural samples. Two milestone papers (Rhadakrishnamurty et al., 1981; Senanayake et al., 1981) both yield very contradictory results. More recent works (Özdemir et al., 1993, see also Dunlop and Özdemir, 1997) show only results from chemically well-identified synthetic (titano)magnetites.

Corresponding high-T susceptibility experiments $(k-T$ curves) indicate in both cases the presence of a single mag- 

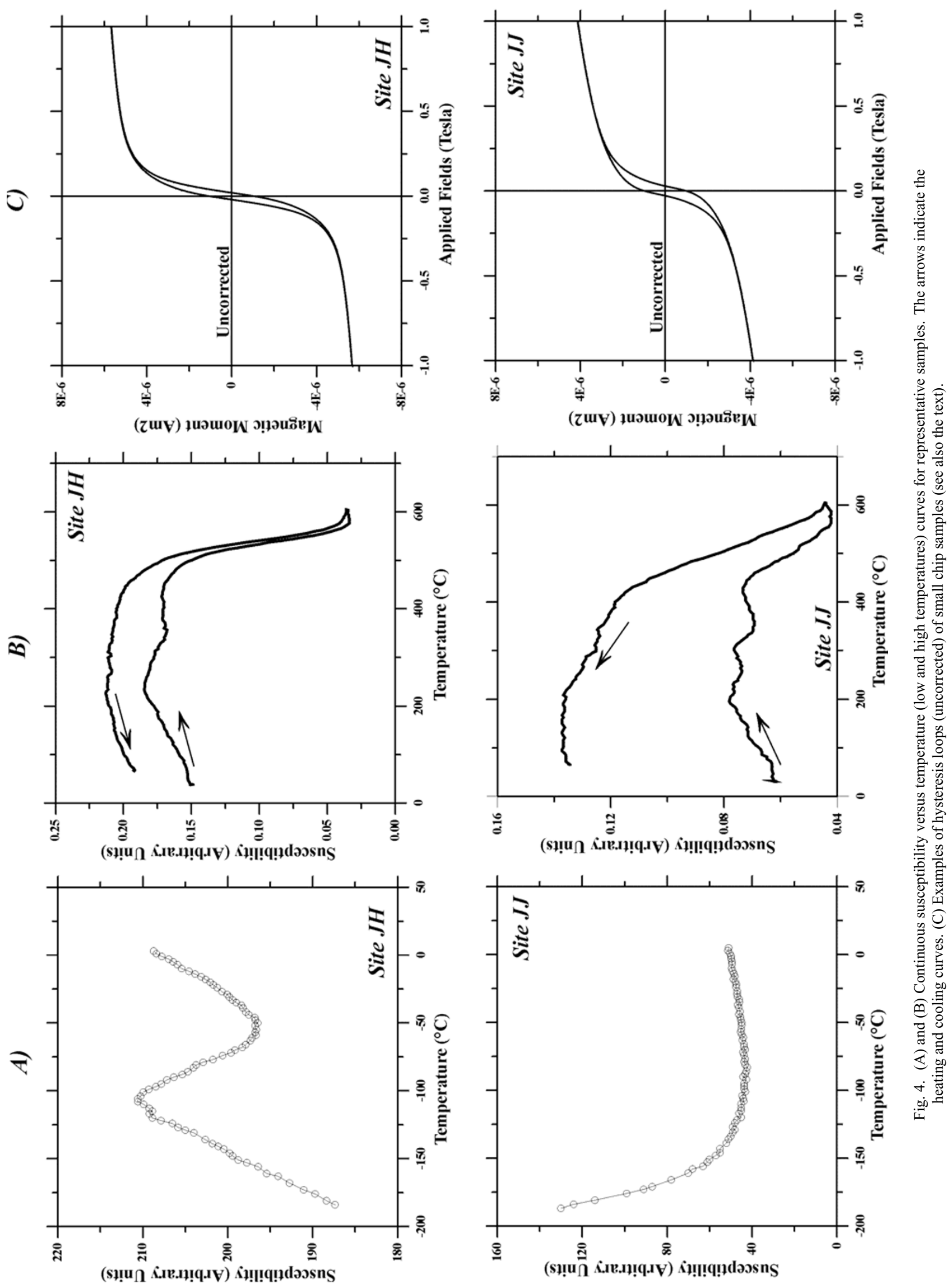


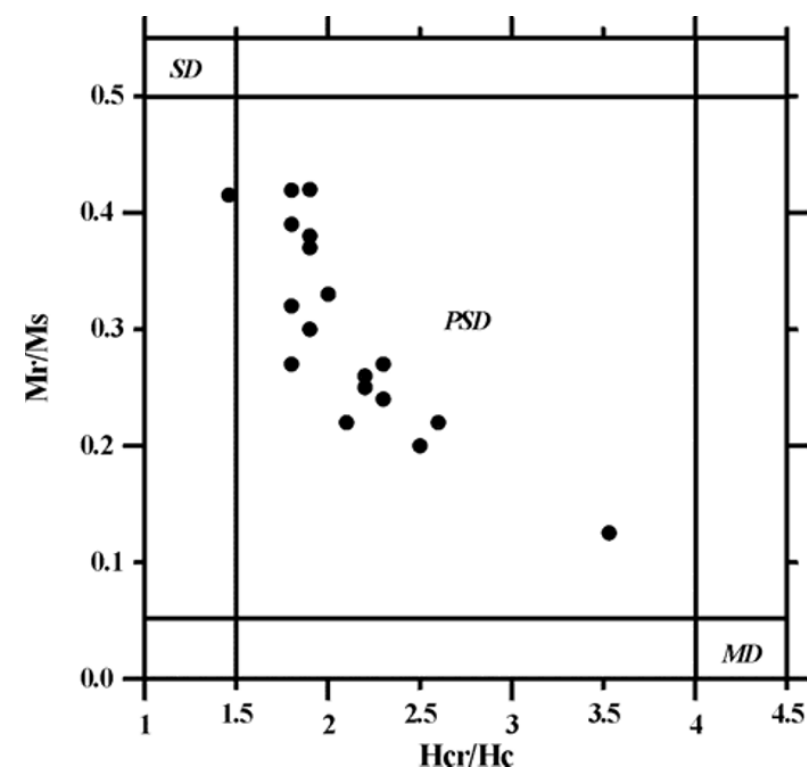

Fig. 5. Day's (1977) diagram showing the possible magnetic domain-type for Mexican Late Quaternary volcanic samples.

netic/ferrimagnetic phase with a Curie point compatible with relatively low-Ti titanomagnetite (around $550^{\circ} \mathrm{C}$, Fig. 4). However, the cooling and heating curves are not perfectly reversible because of the relatively low signal of initial magnetic susceptibility. Let us point out here that we were not able to observe the Curie point of (titano)hematite on the $k-T$ curves. Microscopic observations on polished sections also indicate that the main magnetic mineral is probably low-Ti titanomagnetite associated with exsolved ilmenite probably formed as a result of oxidation of titanomagnetite during the initial flow cooling. These intergrowths typically develop higher than $600^{\circ} \mathrm{C}$ (Haggerty, 1976) and, consequently, the NRM carried by these samples should be a thermoremanent (TRM) magnetization.

\subsection{Hysteresis measurements}

Hysteresis measurements at room temperature were performed on all studied samples using the AGFM 'Micromag' apparatus of the paleomagnetic laboratory at Mexico City in fields up to $1 \mathrm{~T}$. The saturation remanent magnetization $\left(J_{r s}\right)$, the saturation magnetization $\left(J_{S}\right)$, and the coercive force $\left(H_{c}\right)$ were calculated after correction for the paramagnetic contribution. The coercivity of remanence $\left(H_{c r}\right)$ was determined by applying a progressively increasing backfield after saturation. Some typical hysteresis plots are reported in the right part of Fig. 4. The curves are symmetrical in all cases. Near the origin, no potbellied and wasp-waisted behavior (Tauxe et al., 1996) was detected, which probably reflects the very restricted ranges of the opaque mineral coercivities. Associated IRM acquisition curves (not shown), which were measured in a $1 \mathrm{~T}$ maximum field, were found to be very similar for all samples. Saturation is reached in moderate fields of the order of 150-300 mT, which points to some fine-grained spinels as remanence carriers. $J_{r s} / J_{s}$ ranges from 0.12 to 0.42 and $H_{c r} / H_{c}$ varies between 1.4 and 3.6 (Fig. 5). Judging from these values, it seems that all samples fall in the pseudo-single-domain (PSD) grain size region, probably indicating a mixture of multidomain (MD) and a significant amount of single-domain (SD) grains (Day, 1977).

\section{Paleointensity Determination}

Paleointensity experiments were performed using the Thellier method (Thellier and Thellier, 1959) in its modified form (Coe et al., 1978). The heatings and coolings were made in the air and in the laboratory field was set to 30 or $50 \mu \mathrm{T}$. Some 10-11 temperature steps were distributed between 200 and $580^{\circ} \mathrm{C}$. Several control heatings (i.e. reinvestigations of results from previous heating steps, commonly referred to as partial TRM (pTRM) checks) were performed throughout the experiments.

Following the paleodirectional and rock-magnetic results, altogether 62 samples, yielding stable magnetization component with relatively high MDF values, elevated blocking temperatures, and reasonably reversible $k-T$ curves, were selected for paleointensity experiments.

Paleointensity data are reported on the Arai-Nagata (Nagata et al., 1963) plots in Fig. 6. We accepted only the following determinations: (1) obtained from at least 5 NRM-TRM points corresponding to a NRM fraction larger than $1 / 3$ (Table 2), (2) yielding a quality factor (Coe et al., 1978) of about 5 or more, and (3) with positive 'pTRM' checks. For these samples, the NRM fraction $f$ used for determining ranges between 0.37 to 0.97 and the quality factor $q$ varies from 4.5 to 97.8 (generally more than 5). Some 42 samples exhibited the above-described behavior and constitute a 'hard core' of the present paleointensity data set. Eight samples yielded apparently linear segments, although lower quality factors, and were discarded in the calculating of mean paleointensity. They are presented in italics in Table 2. No significant changes of magnetic susceptibilities were detected for these samples after each double heating step, which discards any important mineralogical changes during heatings.

\section{Discussion and Main Results}

We consider the paleomagnetic components determined in this study to be of primary origin for several reasons: (1) thermomagnetic curves show that the remanence is carried in most cases by the 'near magnetite' phase. (2) Reflected light microscopy shows that this (titano)magnetite results from the oxi-exsolution of the original titanomagnetite during the initial flow cooling, which most probably indicates the thermoremanent origin of the primary magnetization. (3) Unblocking temperature spectra and relatively high MDF values point to a small pseudo-single domain low-Ti titanomagnetite as being responsible for remanent magnetization, and (4) single-component, linear demagnetization plots were observed in $75 \%$ of cases.

Paleomagnetic results of the present study yield a $D=$ $359.4^{\circ}, I=27^{\circ}, k=28, \alpha_{95}=11.8^{\circ}$, direction. No significant difference can be recognized with the expected PlioQuaternary paleodirection (Besse and Courtillot, 1991). Nevertheless, if paleodeclinations of individual sites are regarded, some deviations from the expected direction can be recognized (Fig. 3), which may be related to paleosecular variation. 

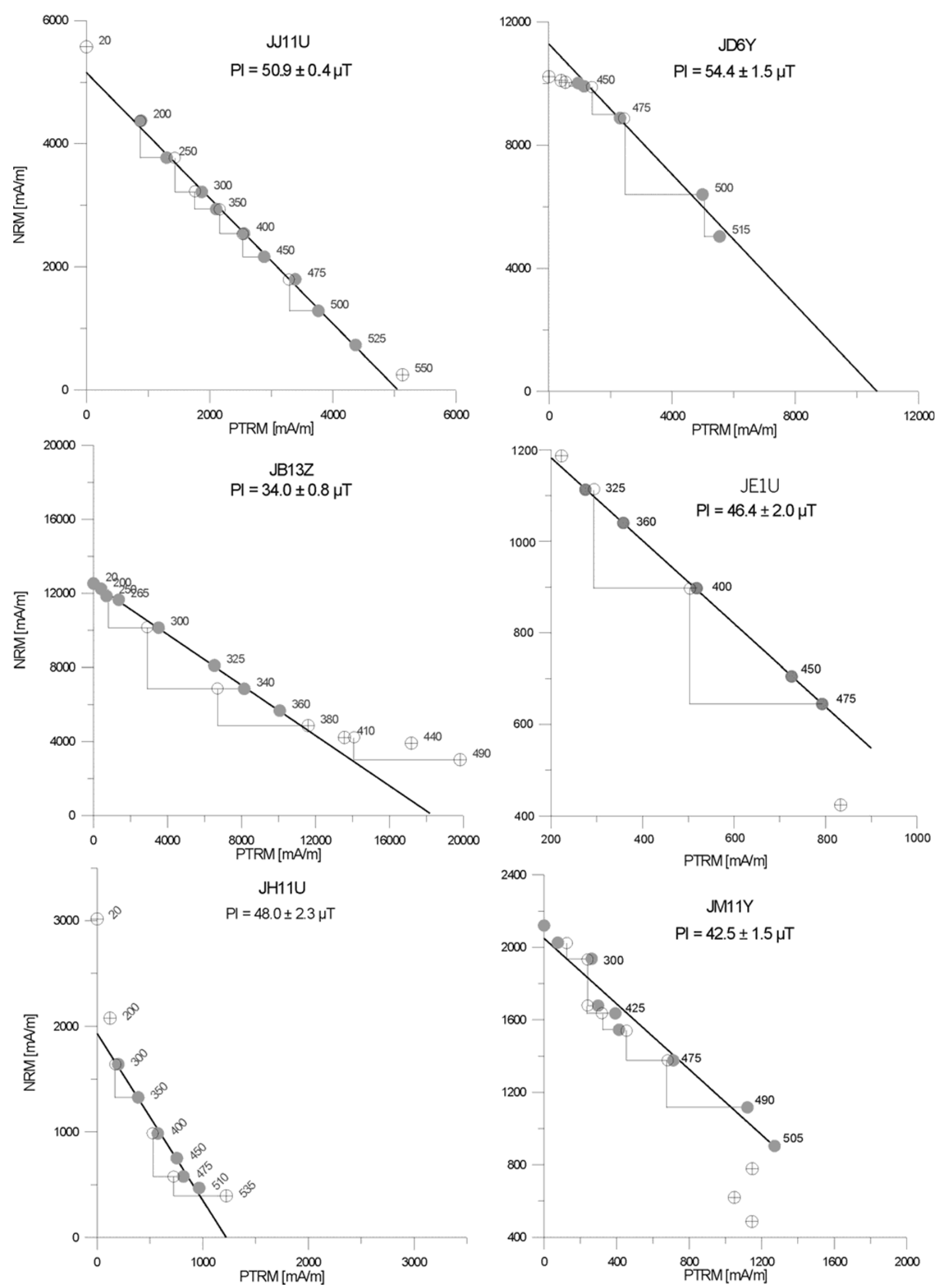

Fig. 6. Representative NRM-TRM (Arai-Nagata) plots for the central Mexican Late Quaternary volcanic lava flows. Open circles refer to the 'pTRM' checks. $\oplus$-Rejected. 
Table 2. Absolute paleointensity results from the central Mexican Late Quaternary lava flows. $T_{\min }-T_{\max }$ is the temperature interval used for paleointensity determination, $N$ is the number of NRM-TRM points used for determination, $f, g$, and $q$ are the fraction of extrapolated NRM used for intensity determination, the gap factor, and the quality factor (Coe et al., 1978), respectively. PI is the individual paleointensity estimate with associated error. Italic font denotes the lower quality determinations which were discarded in site-mean paleointensity calculation (see the text).

\begin{tabular}{|c|c|c|c|c|c|c|c|}
\hline Sample & $T_{\min }-T_{\max }$ & $N$ & $g$ & $f$ & $q$ & PI (microT) & S.D. \\
\hline JM5X & $200-475$ & 6 & 0.764 & 0.477 & 12.3 & 55.7 & 1.7 \\
\hline JM6X & $200-500$ & 7 & 0.808 & 0.469 & 8.8 & 60.5 & 2.6 \\
\hline JM7X & $200-500$ & 7 & 0.818 & 0.387 & 4.5 & 57.0 & 4.1 \\
\hline$J M 9 X$ & $425-525$ & 5 & 0.725 & 0.214 & 2.0 & 58.0 & 4.6 \\
\hline JM10X & $20-490$ & 8 & 0.810 & 0.606 & 24.8 & 53.0 & 1.1 \\
\hline JM10Y & $20-475$ & 7 & 0.793 & 0.427 & 5.6 & 57.5 & 3.5 \\
\hline JM11X & $200-500$ & 7 & 0.790 & 0.569 & 12.2 & 44.9 & 1.7 \\
\hline JM11Y & $20-505$ & 9 & 0.841 & 0.608 & 14.5 & 42.5 & 1.5 \\
\hline JM12X & $200-475$ & 6 & 0.780 & 0.604 & 52.2 & 55.4 & 0.5 \\
\hline JM12Y & $20-475$ & 7 & 0.824 & 0.723 & 47.6 & 64.0 & 0.8 \\
\hline Mean & 9 Samples & & & & & 54.8 & 6.6 \\
\hline JH10Y & $300-510$ & 6 & 0.772 & 0.577 & 20.1 & 37.9 & 1.4 \\
\hline JH10Z & $300-475$ & 5 & 0.608 & 0.614 & 15.3 & 34.3 & 1.4 \\
\hline JH11U & $300-510$ & 6 & 0.773 & 0.604 & 16.6 & 48.0 & 2.3 \\
\hline JH11Y & $300-510$ & 6 & 0.779 & 0.635 & 27.8 & 47.2 & 1.4 \\
\hline JH12Y & $200-510$ & 7 & 0.816 & 0.771 & 53.8 & 41.0 & 0.8 \\
\hline JH12Z & $300-510$ & 6 & 0.774 & 0.634 & 13.7 & 41.9 & 2.5 \\
\hline$J H 14 X$ & $450-520$ & 5 & 0.723 & 0.467 & 1.7 & 41.0 & 8.0 \\
\hline$J H 14 Y$ & $450-520$ & 5 & 0.692 & 0.603 & 3.5 & 31.2 & 3.8 \\
\hline JH17Z & $300-510$ & 6 & 0.751 & 0.606 & 55.8 & 47.8 & 0.7 \\
\hline Mean & 7 Samples & & & & & 41.1 & 6.0 \\
\hline $\mathrm{JJ} 2 \mathrm{Y}$ & $20-450$ & 7 & 0.795 & 0.897 & 54.2 & 45.6 & \\
\hline $\mathrm{JJ} 10$ & $300-535$ & 8 & 0.840 & 0.676 & 15.7 & 62.3 & 2.3 \\
\hline JJ11U & $200-525$ & 9 & 0.868 & 0.706 & 77.9 & 50.9 & 0.4 \\
\hline JJ11V & $200-475$ & 7 & 0.818 & 0.554 & 31.7 & 45.5 & 0.7 \\
\hline JJ11X & $400-525$ & 5 & 0.746 & 0.477 & 26.8 & 75.4 & 1.0 \\
\hline JJ11Y & $400-525$ & 5 & 0.750 & 0.343 & 16.1 & 87.9 & 1.4 \\
\hline $\mathrm{JJ} 11 \mathrm{Z}$ & $250-550$ & 9 & 0.848 & 0.695 & 14.0 & 57.0 & 2.4 \\
\hline JJ12 & $250-535$ & 9 & 0.846 & 0.754 & 25.7 & 66.6 & 1.7 \\
\hline Mean & 8 Samples & & & & & 61.4 & 14.9 \\
\hline JB9Z & $250-305$ & 5 & 0.687 & 0.387 & 8.1 & 21.4 & 0.7 \\
\hline JB9U & $250-305$ & 5 & 0.673 & 0.509 & 9.2 & 20.1 & 0.8 \\
\hline JB10X & $305-450$ & 5 & 0.667 & 0.750 & 4.9 & 13.4 & 1.4 \\
\hline$J B 10 Y$ & $305-450$ & 5 & 0.687 & 0.689 & 2.6 & 12.2 & 2.3 \\
\hline JB12X & $290-380$ & 5 & 0.732 & 0.370 & 5.9 & 27.2 & 1.3 \\
\hline JB12Y & $265-380$ & 7 & 0.811 & 0.667 & 14.3 & 26.4 & 1.0 \\
\hline JB13U & $20-360$ & 8 & 0.773 & 0.608 & 37.7 & 34.1 & 0.4 \\
\hline$J B 13 X$ & $20-410$ & 10 & 0.860 & 0.267 & 4.7 & 36.7 & 1.8 \\
\hline JB13Y & $20-360$ & 8 & 0.792 & 0.432 & 8.7 & 33.2 & 1.3 \\
\hline JB13Z & $20-360$ & 8 & 0.795 & 0.549 & 19.8 & 34.0 & 0.8 \\
\hline Mean & 8 Samples & & & & & 25.9 & 8.8 \\
\hline JD4X & $20-575$ & 7 & 0.844 & 0.869 & 51.3 & 52.5 & 0.8 \\
\hline$J D 4 Y$ & $350-515$ & 5 & 0.746 & 0.220 & 1.4 & 68.0 & 8.0 \\
\hline JD5X & $20-575$ & 7 & 0.771 & 0.971 & 97.8 & 45.8 & 0.4 \\
\hline$J D 5 Y$ & $350-500$ & 4 & 0.553 & 0.192 & 0.9 & 42.6 & 4.9 \\
\hline JD6X & $20-575$ & 7 & 0.720 & 0.892 & 97.5 & 53.2 & 0.4 \\
\hline JD6Y & $450-515$ & 4 & 0.602 & 0.431 & 9.7 & 54.4 & 1.5 \\
\hline JD7 & $450-575$ & 5 & 0.699 & 0.767 & 19.6 & 69.6 & 1.9 \\
\hline JD8 & $20-575$ & 7 & 0.826 & 0.784 & 43.6 & 60.6 & 0.9 \\
\hline Mean & 6 Samples & & & & & 55.8 & 9.7 \\
\hline JE1Z & $325-525$ & 6 & 0.745 & 0.511 & 9.6 & 61.7 & 2.5 \\
\hline $\mathrm{JE} 1 \mathrm{U}$ & $300-475$ & 6 & 0.756 & 0.394 & 7.1 & 46.4 & 2.0 \\
\hline$J E 2 X$ & $300-475$ & 6 & 0.761 & 0.385 & 3.5 & 49.1 & 4.2 \\
\hline JE2Y & $300-475$ & 6 & 0.781 & 0.430 & 5.3 & 53.9 & 3.4 \\
\hline JE6Y & $350-525$ & 5 & 0.674 & 0.444 & 7.4 & 85.9 & 3.5 \\
\hline Mean & 4 Samples & & & & & 59.4 & 15.9 \\
\hline
\end{tabular}


Table 3. Summary of absolute geomagnetic paleointensities and virtual dipole moments (selected using the same acceptance criteria as in the present study) for Mexican Latest Pleistocene to Holocene lava flows (from Thellier paleointensity experiments only, see also the text). $N$ refers to the number of cooling units used to calculate the average paleointensity $(F)$ and VDM. $n$ refers to the number of individual samples for each cooling unit.

\begin{tabular}{lcccccc}
\hline \multicolumn{1}{c}{ Reference } & Age (Years BP) & $N$ & $n$ & $F \pm \sigma_{F}(\mathrm{~T})$ & VDM $\left(10^{22} \mathrm{Am}^{2}\right)$ & S.D. \\
\hline Böhnel et al. (1997) & $\sim 2000$ & 1 & 32 & $72.1 \pm 14.2$ & 16.0 & 3.2 \\
Gonzalez-Huesca et al. (1997) & $19000-2000$ & 5 & 12 & $48.2 \pm 20.6$ & 10.7 & 4.6 \\
This Study & $39000-2000$ & 6 & 42 & $49.7 \pm 13.6$ & 11.8 & 2.6 \\
\hline All VDMs & & 12 & 86 & & 12.8 & 2.8 \\
\hline
\end{tabular}
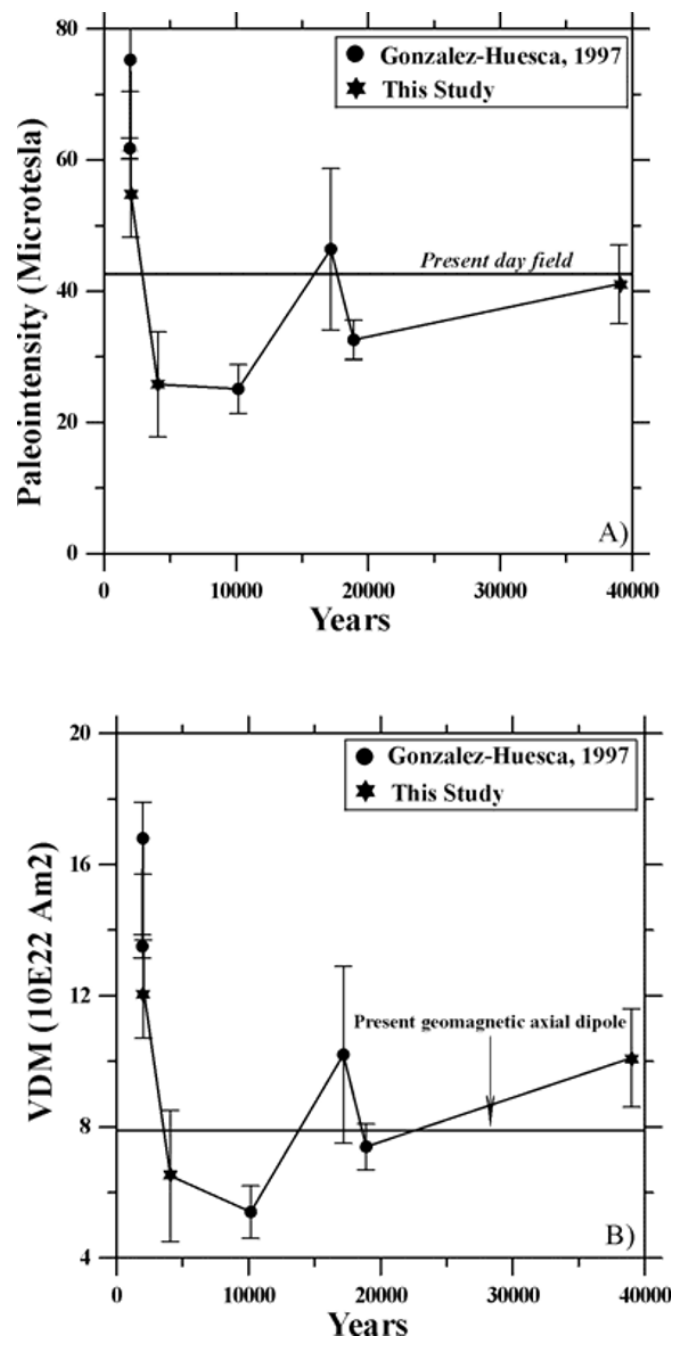

Fig. 7. Evolution of individual paleointensities (a) and virtual dipole moments (b) during the Latest Pleistocene to Holocene time (only results with available radiometric ages are shown) according to selected absolute intensity data from central Mexico (see also the text).

As far as the preliminary palaeointensity experiments are concerned, absolute geomagnetic intensities obtained from Mexican volcanic lava flows vary from 25.9 to $61.4 \mu \mathrm{T}$. The mean value is $49.7 \pm 13.6 \mu \mathrm{T}$. The corresponding mean virtual dipole moment (VDM) is $11.8 \pm 2.6 \times 10^{22} \mathrm{Am}^{2}$, which is almost double compared to the mean paleointensity for the last $50 \mathrm{ky}(6.5 \pm 3.3)$ according to the selected paleointensity data from the IAGA paleointensity database (so-called Montpellier paleointensity database at ftp://ftp. dstu.univ-montp2.fr/pub/paleointb, see also Perrin and Shcherbakov, 1997). The average value obtained in the present study, which may be affected by short-term secular variation, is also almost double compared to the mean paleointensity of between 0.3 and $5 \mathrm{My}$, recently reported by Juàrez and Tauxe (2000) and substantially higher than the present-day geomagnetic field strength (about $8 \times$ $10^{22} \mathrm{Am}^{2}$ ). Relatively high paleointensities were already reported in Nagata et al.'s (1965) pioneering work for some Mexican Quaternary volcanic and archeomagnetic materials. These results have remained essentially unchallenged during the last decade (Gonzalez-Huesca et al., 1997; Urrutia-Fucugauchi, 1996).

Our results, although not numerous, are of high technical quality, as attested by reasonably high Coe et al. (1978) quality factors. It is quite hard to assess the reliability of the paleointensity results, due to the poor documentation of many previously published determinations. In our analyses of the Quaternary paleointensity data from Mexico, we consider only results obtained with the Thellier method for which positive PTRM checks attest the absence of alteration during heatings and at least two determinations per flow. Moreover, we imposed the same acceptance criteria on the individual determinations that we use in the present study (i.e. NRM fraction used for a paleointensity determination larger than $1 / 3$ and a quality factor of around or above 5). No transitional data will be used in analyses. From more than 30 absolute paleointensity determinations only five belonging to Gonzalez-Huesca et al. (1997) and one from Böhnel et al. (1997) fulfill these basic criteria (Table 3, Fig. 7). Combining all reliable paleointensity data currently available from Mexico for the last $50 \mathrm{Ky}$, we obtain a mean VDM equal to $12.8 \pm 2.6 \times 10^{22}$. It should be noted that there are not enough data to discuss VDM variation through time (Fig. 7) and more determinations are greatly needed.

The individual paleointensity we obtained for about 2000 BP (Fig. 7), is higher than the present field intensity (43 $\mathrm{mT})$. This is in broad agreement with southern U.S.A. (Sternberg, 1989) and worldwide (McElhinny and Senanayake, 1982) archeomagnetic results. Barbetti (1983), however, reported somewhat contradictory results studying southeast Australia aboriginal fireplaces and baked clay. High paleointensity occurrence (some $40 \%$ higher than the present field strength) around $2000 \mathrm{BP}$ has been speculated by some authors (Aitken et al., 1989; Böhnel et al., 1997). Our study furnishes evidence fostering that speculation.

Acknowledgments. The comments of Elisabeth Schnepp, 
Daisuke Miki and Hidefumi Tanaka on an early version of this manuscript lead to significant improvements of the scientific content and English style of this paper. The authors are grateful for the financial support given by CONACYT project J32727-T.

\section{References}

Aitken, M. J., A. Allsop, G. Bussel, and M. Winter, Geomagnetic intensity variation during the last 4000 years, Phys. Earth Planet. Int., 56, 49-58 1989.

Barbetti, M., Archaomagnetic results from Australia, in Geomagnetism of Backed Clays and Recent Sediments, pp. 173-175, Elsevier, Amsterdam, 1983.

Besse, J. and V. Courtillot, Revised and synthetic apparent polar wander paths of the African, Eurasian, North American and Indian Plates, and true polar wander since $200 \mathrm{Ma}$, J. Geophys. Res., 96, 4029-4050, 1991.

Böhnel, H., J. Morales, C. Caballero, L. Alva, G. McIntosh, S. Gonzalez, and G. J. Sherwood, Variation of rock-magnetic parameters and paleoinetsnities over a single Holocene lava flow, J. Geomag. Geoelectr., 49, 523-542, 1997.

Coe, R., S. Grommé, and E. A. Mankinen, Geomagnetic paleointensity from radiocarbon-dated flows on Hawaii and the question of the Pacific nondipole low, J. Geophys. Res., 83, 1740-1756, 1978.

Coe, R., L. Hongre, and G. A. Glatzmaier, An examination of simulated geomagnetic reversals from a paleomagnetic perspective, Phil. Trans. Roy. Soc. London, Ser. A, 357, 1787-1813, 2000.

Day, R., M. Fuller, and V. A. Schmidt, Hysteresis properties of titanomagnetites: Grain-size and compositional dependence, Phys. Earth Planet. Int., 13, 260-267, 1977.

Dunlop, D. and Ö. Özdemir, Rock-Magnetism, fundamentals and frontiers, Cambrige University Press, 573 pp., 1997.

Glatzmaier, G. A., R. S. Coe, L. Hongre, and P. H. Roberts, The role of the Earth's mantle in controlling the frequency of geomagnetic reversals, Nature, 401, 885-890, 1999.

Goguitchaichvili, A., M. Prévot, and P. Camps, No evidence for strong fields during the R3-N3 Icelandic geomagnetic reversals, Earth Planet. Sci. Lett., 167, 15-34, 1999.

Gonzalez-Huesca, I. S., La variacion secular en México Central durante los ultimos 30000 años por medio del estudio magnetico de lavas, Ph.D. thesis, Univ. Mexico, 1992.

Gonzalez-Huesca, I. S., G. Sherwood, H. Böhnel, and E. Schnepp, Palaeosecular variation in Central Mexico over the last 30000 years: the record from lavas, Geophys. J. Int., 130, 201-219, 1997.

Haggerty, S. E., Oxidation of opaque mineral oxides in basalts, in Oxide Minerals, Mineral. Soc. Amer., 3, 300 pp., 1976.

Juàrez, M. T. and L. Tauxe, The intensity of the time-averaged geomagnetic field: the last 5 Myr, Earth Planet. Sci. Lett., 175, 169-180, 2000.

Kirschvink, J. L., The least-square line and plane and analysis of palaeomagnetic data, Geophys. J. R. Astron. Soc., 62, 699-718, 1980.

Kosterov, A. and M. Prévot, Possible mechanisms causing failure of Thellier paleointensity experiments : results of rock-magnetic study of the Lesotho basalt, Southern Africa, Geophys. J. Int., 134, 554-572, 1998.
McElhinny, M. W. and W. E. Senanayake, Variation of the geomagnetic dipole 1: the past 50,000 years, J. Geomag. Geoelectr., 34, 39-51, 1982.

Mora-Alvarez, G., C. Caballero, J. Urrutia-Fucugauchi, and Sh. Uchiumi, Southward migration of volcanic activity in the Sierra de Las Cruces, basin of Mexico: A preliminary K-Ar dating and paleomagnetic study, Geofisica Internacional, 30, 61-70, 1991.

Nagata, T., Y. Arai, and K. Momose, Secular variation of the geomagnetic total force during the last 5000 years, J. Geophys. Res., 68, 5277-5281, 1963.

Nagata, T., K. Kobayashi, and E. J. Schwarz, Archeomagnetic intensity studies of south and central America, J. Geomag. Geoelectr., 17, 399405, 1965.

Özdemir, O., D. Dunlop, and B. M. Moskowitz, The effect of oxidation on the Verwey transition in magnetite, Geophys. Res. Lett., 20, 1671-1674, 1993.

Perrin, M. and V. P. Shcherbakov, Paleointensity of the earth magnetic field for the past $400 \mathrm{My}$ : evidence for a dipole structure during the Mesozoic low, J. Geomag. Geolectr., 49, 601-614, 1997.

Perrin, M., E. Schnepp, and V. Shcherbakov, Paleointensity database updated, EOS, 79, 198, 1998.

Prévot, M., E. A. Mainkinen, S. Grommé, and A. Lecaille, High paleointensity of the geomagnetic field from thermomagnetic studies on rift valley pillow basalts from the middle Atlantic ridge, J. Geophys. Res., $\mathbf{8 8}$, 2316-2326, 1983

Prévot, M., M. Derder, M. M. McWilliams, and J. Thompson, Intensity of the Earth's magnetic field: evidence for a Mesozoic dipole low, Earth Planet. Sci. Lett., 97, 129-139, 1990.

Rahdakrishnamurty, C., S. D. Likhite, E. R. Deutsh, and G. S. Murthy, On the complex magnetic behaviour of titanomagnetites, Phys. Earth Planet. Int., 30, 281-290, 1981.

Senanayake, W. E. and M. W. McElhinny, Hysteresis and susceptibility characteristics of magnetites and titanomagnetites: Interpretation of results from basaltic rocks, Phys. Earth Planet. Int., 26, 47-55, 1981.

Sternberg, R. S., Archeomagnetic paleointensity in the American soutwest during the last 2000 years, Phys. Earth. Planet. Int., 56, 1-17, 1989.

Tauxe, L., T. A. T. Mullender, and T. Pick, Pot-bellies, wasp-waists and superparamagnetism in magnetic hysteresis, J. Geophys. Res., 95, $12337-$ 12350, 1996.

Thellier, E. and O. Thellier, Sur l'intensité du champ magnétique terrestre dans le passé historique et géologique, Ann. Géophysique., 15, 285-376 1959.

Urrutia-Fucugauchi, J., Palaeomagnetic study of the Xitle-Pedregal de San Angel lava flow, southern Basin of Mexico, Phys. Earth Planet. Int., 97, 177-196, 1996.

Urrutia-Fucugauchi, J. and L. Martin del Pozzo, Implicaciones de los datos paleomagneticos sobre la edad de la Sierra de Chichinautzin, cuenca de Mexico, Geofisica Internacional, 32, 523-533, 1993.

J. Morales, A. Goguitchaichvili (e-mail: avto@tonatiuh.igeofcu.unam. $\mathrm{mx}$ ), and J. Urrutia-Fucugauchi 